\title{
BuCKLING CHARACTERISTICS STUdy OF Iso'Truss Structure With Different Positions of LONGITUDINAL MEMBERS
}

\author{
M. Gavade ${ }^{1}$ and S. Roy ${ }^{2}$ \\ ${ }^{2}$ R\&DE (E), Defence Research \& Development Organisation, Pune-411015, India
}

\begin{abstract}
The present paper illustrates a light weight composite IsoTruss structure and its characteristics in buckling through finite element modelling and simulations. IsoTruss provides excellent opportunities to enhance the strength to weight ratio of a structural element. The paper presents the comparative study of compressive buckling load carrying capacity with respect to bay length of IsoTruss under placement of longitudinal members at different location along the axis of IsoTruss. The study concludes that the IsoTruss exhibits global as well as local buckling characteristics for progressive bay length of IsoTruss. The IsoTruss with longitudinal members placed away from axis has better compressive buckling load carrying ability than the IsoTruss with longitudinal members nearer to the axis of the IsoTruss.
\end{abstract}

\section{KEYWORDS}

IsoTruss, critical load, longitudinal members, helical members, Bay length, buckling analysis, global buckling, local buckling, Carbon fibre, tensile test.

\section{INTRODUCTION}

The IsoTruss structure classified as an open lattice structure. Open lattice structure is a regular, periodic configuration of points, particles or objects throughout an area or a space, especially the arrangement of ions or molecules in a crystalline solid. It could be made of strips of metal, wood, or similar material overlapped or overlaid in a regular, usually crisscross pattern. Compare to convectional beam, column and tubular structural member load carrying capacity of IsoTruss structure is more, very precisely its strength to weight ratio is more due to its unique lattice structural configuration. Figure $2 \mathrm{~b}$ shows a typically eight nodded IsoTruss structure. It has a longitudinal member as well as helical member. Longitudinal members could be design to carry bending and compressive load and helical member for torsion loads. Therefore its performance is better than the conventional structural member for the load combination of bending, compression and torsion load. The bay length is the distance between the successive repeating structures of the IsoTruss. The axis of IsoTruss is the profile passing through the centres of the geometry of the cross section. The helical members are which spirals about the axis of IsoTruss along the profile decided by the number of nodes as shown in Figure 1. The longitudinal members are positioned along the axis of the IsoTruss through the intersection of helical members of IsoTruss. Outside diameter is the diameter of the circle encircling the extremes of the cross section of the IsoTruss. The tetrahedrons are at the outermost region of the cross section of IsoTruss. The helical members while spiralling about the axis of IsoTruss give rise to a tetrahedron structure at the outermost part of the cross section of IsoTruss. The helical members which spirals around the longitudinal members stretched along the length of IsoTruss provide torsion strength, while the longitudinal members placed along the length provides tensile, compressive and as well as DOI: $10.5121 /$ ijci.2016.5121 
bending strength. Number of nodes represents the geometry of the cross section of IsoTruss. Number of nodes decides the profile of the helical members. A six node IsoTruss represents a cross section of IsoTruss with two triangles 180 degree with respect to each other as shown in Figure 2a. An eight node configuration has two squares as shown in Figure 2b. A 10 node configuration will have two pentagons as shown in Figure 2c. IsoTruss structures have been manufactured using several different methods [1-6]. In the present study material used for IsoTruss is $24 \mathrm{~K}$ carbon fibre cordage impregnated with epoxy resin. The local and global compressive buckling behaviour of 8-noded IsoTruss has been studied by Rackliffe et. al.[7]. It has observed that local buckling depends on bay length, for shorter bay lengths higher the buckling loads. Global buckling, on the other hand, is independent of bay length. In the present study longitudinal members of the IsoTruss placed at the different intersection of helical members along the IsoTruss axis. The position of these longitudinal members on the IsoTruss affects the buckling characteristics of the IsoTruss, which is examined in the following study.

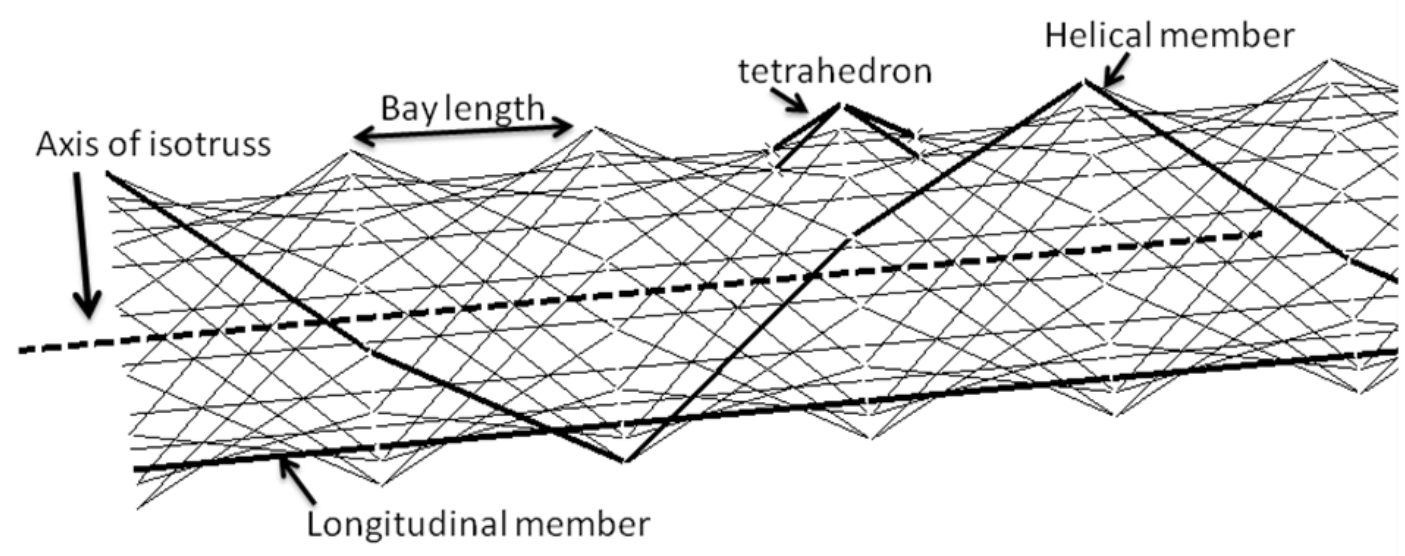

Figure 1. IsoTruss of eight node configuration

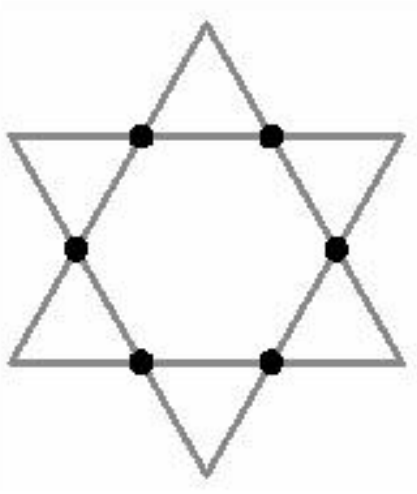

$2 \mathrm{a}$

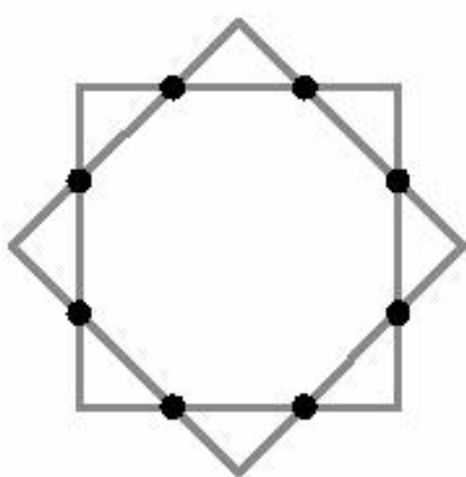

$2 b$

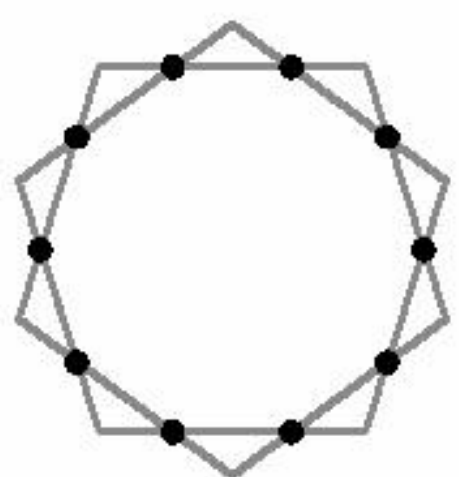

$2 \mathrm{c}$

Figure 2. IsoTruss cross section having different node

\section{Material Characterization}

In the present study material used for IsoTruss is $24 \mathrm{~K}$ carbon fibre cordage impregnated with epoxy resin. To investigate the material properties of resin impregnated carbon cordages, tensile specimens has been prepared and tested. Photograph 3 shows a typical specimen used for tensile 
International Journal on Cybernetics \& Informatics (IJCI) Vol. 5, No. 1, February 2016

test. Specimens are prepared using Rein Film Infusion (RFI) process with a curing temp of $80^{\circ} \mathrm{C}$ for $1 \mathrm{hr}$. Diameter of the each carbon cordage specimen becomes $2 \mathrm{~mm}$ and density is 0.0024 gms/cubic meter after infusion. Specimens are tested in universal testing machine (UTM) as shown in Photograph 2. Figure 3 shows stress-strain graph from which the Modulus of elasticity is determined as $250 \mathrm{GPa}$. Table 1 shows the material properties of the carbon cordages used in FE analysis.

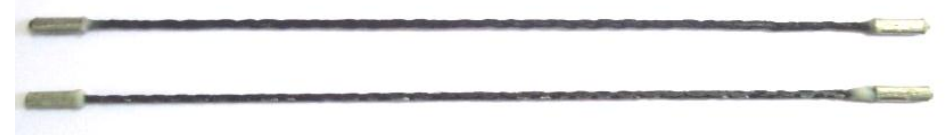

Photograph 1. Tensile test specimen

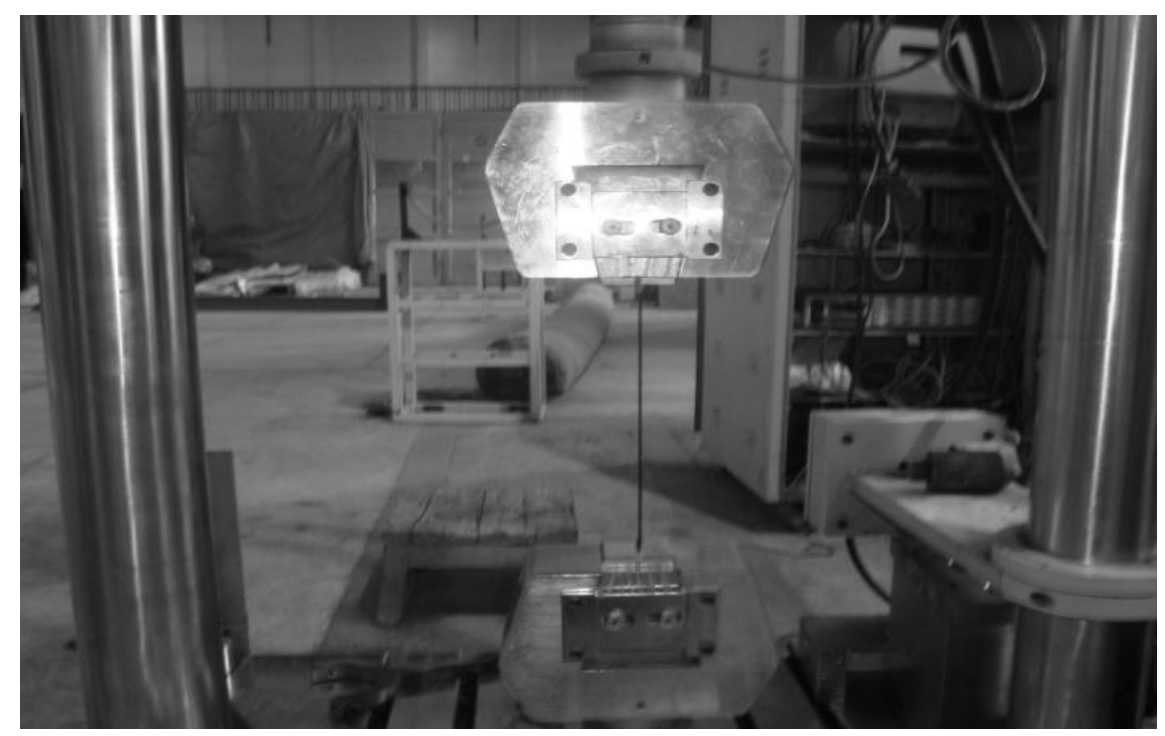

Photograph 2. Specimen on UTM for testing

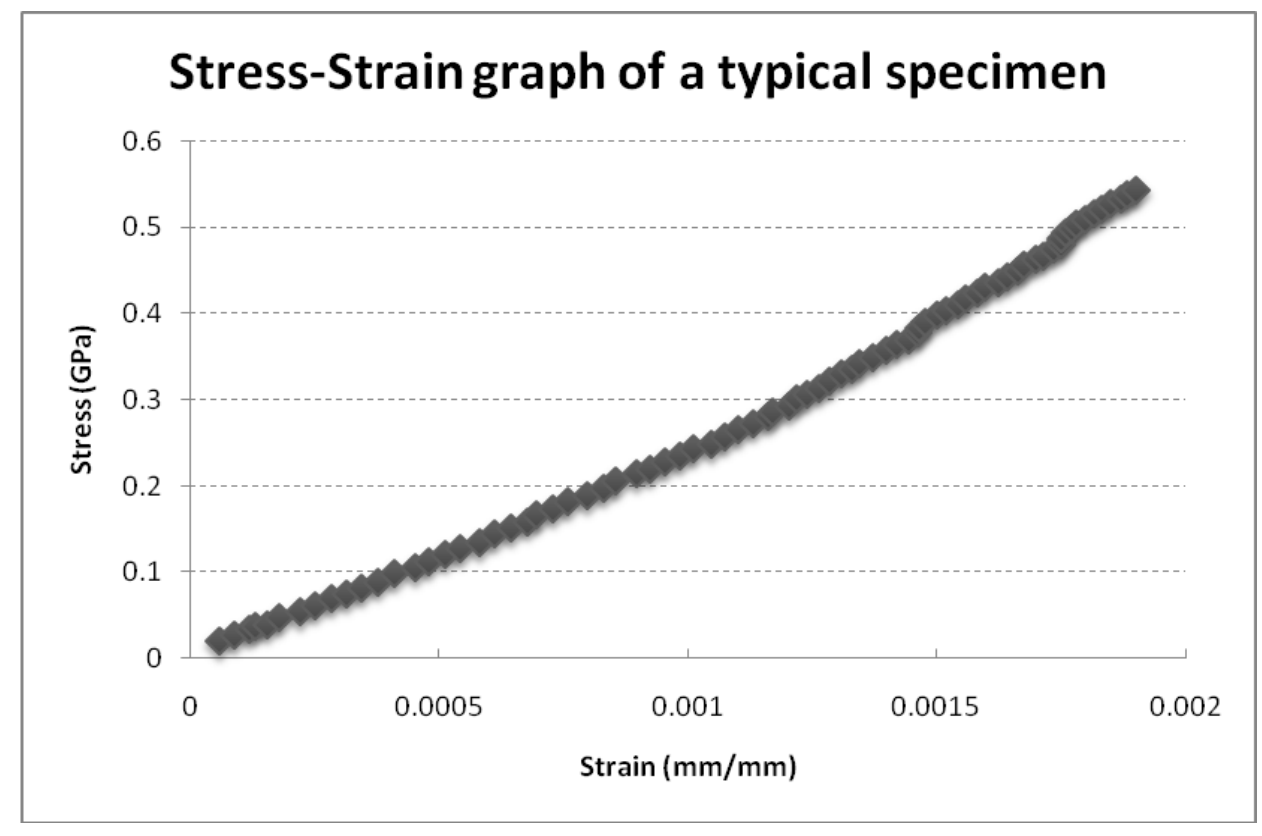

Figure 3. Stress-strain graph of a typical specimen 
International Journal on Cybernetics \& Informatics (IJCI) Vol. 5, No. 1, February 2016

Table 1. Material Properties of $24 \mathrm{k}$ carbon cordage with impregnated resin

\begin{tabular}{|c|c|}
\hline Modulus of Elasticity (GPa) & 250 \\
\hline Density (gms/cubic meter) & 0.0024 \\
\hline Diameter of carbon fibre thread(mm) & 2 \\
\hline
\end{tabular}

\section{FINITE ELEMENT MODELLING AND BUCKLING ANALYSIS}

Three different types of eight nodded IsoTruss have been considered for FE analysis as follows

Type 1: IsoTruss with longitudinal members at the base of the tetrahedron abbreviated as IL (i.e. Internal longitudinal member), as shown in Figure 4a.

Type 2: IsoTruss with longitudinal members at the uppermost point or vertex of the tetrahedron abbreviated as EL (i.e. External longitudinal member), as shown in Figure 4b.

Type 3: IsoTruss with longitudinal members at vertex and base points of the tetrahedron abbreviated as IEL (i.e. Internal \& External Longitudinal members), as shown in Figure 4c.

Figure $5 \mathrm{a}, 5 \mathrm{~b}$ and $5 \mathrm{c}$ shows the cross-section of the IL, EL and Type IEL IsoTruss respectively.

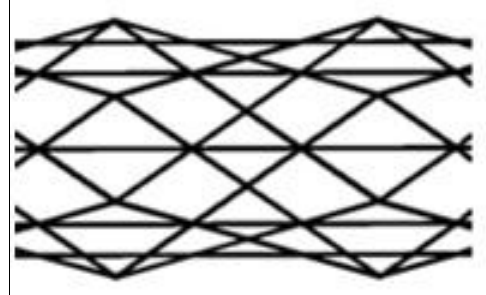

4(a)

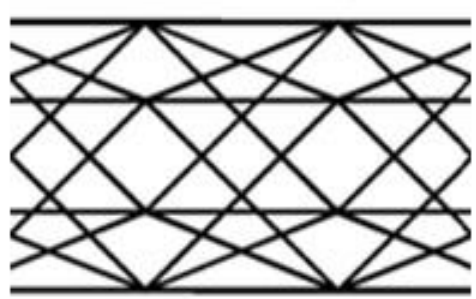

4(b)

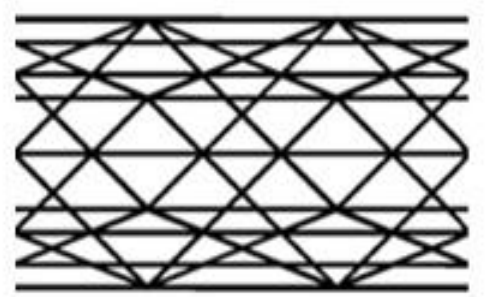

$4(c)$

Figure 4. IsoTruss having longitudinal member at different location

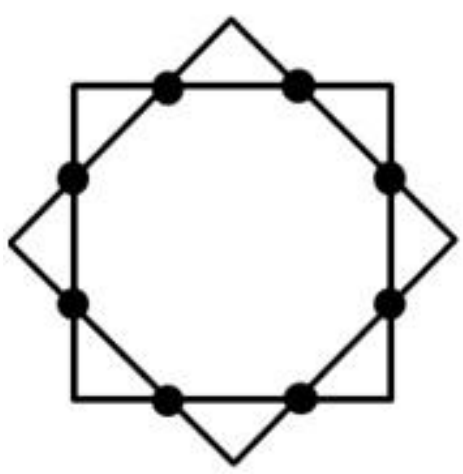

$5(a)$

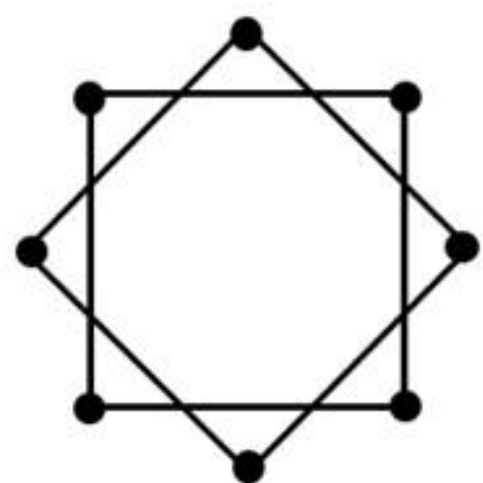

$5(\mathrm{~b})$

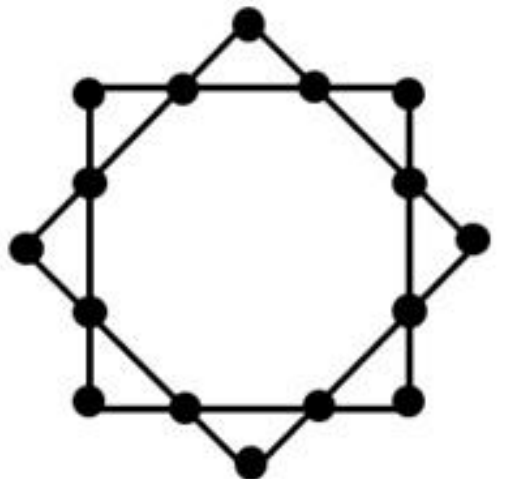

$5(\mathrm{c})$

Figure 5. IsoTruss having longitudinal member at different location(cross sectional view)

In the present study IsoTruss considered for the buckling analysis is of eight node configuration. The outer diameter of the truss is $106 \mathrm{~mm}$ and total length is 1.5 meters. Finite element (FE) model of the IsoTruss has been prepared using ABAQUS 6.10 FE software. IsoTruss is modelled using 2 node linear beam element. 
The compressive load carrying capacity can be determined considering Euler's buckling formulation of columns. The compressive load carrying capacity of a column with one end fixed and one end free is given by the critical load $\mathrm{P}_{\text {cr. }}$

$P_{c r}=\frac{\pi^{2} E I}{4 L^{2}}$

Where, $\mathrm{E}$ is modulus of elasticity of the material, $\mathrm{n}$ is number of mode, $\mathrm{I}$ is Moment of Inertia, $\mathrm{L}$ is the Length of the column.

As per the Equation 1 the critical load is proportional to moment of inertia. The moment of inertia is directly proportional to the distribution of the mass along the neutral axis. Thus Moment of inertia will increase if the longitudinal members are placed away from the neutral axis which passes from the centre point the IsoTruss (as IsoTruss is a symmetric structure in cross section).Thus the IsoTruss-EL and IsoTruss-IEL are expected to have better compressive handling capacity than IsoTruss-IL.

In the present study buckling characteristics study has been done using ABAQUS 6.10 FE software. During analysis one end of the IsoTruss is constrained for all degrees of freedom and on the other end a reference load of $1 \mathrm{~N}$ is applied. FE analysis gives the load factor (Eigen value) for the IsoTruss and using Equation 2, the load carrying capacity of the IsoTruss is determined.

$$
P=P_{r}+\left(\lambda \times P_{r}\right)
$$

Where $P_{r}$ is the reference load, $\lambda$ is the load factor and $P$ is the critical buckling load the truss can carry safely.

\section{RESUlTs \& DisCUSSION}

The Figure 6 illustrates the compressive buckling load carrying capacity for IsoTruss IL, EL and IEL as a function of bay length of the IsoTruss. From the Figure 6 it can be observe that the critical buckling load decreases as the bay length increases for all three types of IsoTruss. For IL and IEL IsoTruss from 50 to $150 \mathrm{~mm}$ bay length buckling load is all most constant. All three types of IsoTruss exhibit a global buckling for a range of bay lengths from $50 \mathrm{~mm}$ to $200 \mathrm{~mm}$. From 200 to $300 \mathrm{~mm}$ bay length there is a transition zone of global to local deformation. IsoTruss with bay length greater than $300 \mathrm{~m}$ shows local buckling behaviour and also exhibit a very small compressive buckling load carrying capacity before buckling. IsoTruss IEL shows maximum buckling load carrying capacity than IsoTruss IL \& EL as expected. 
International Journal on Cybernetics \& Informatics (IJCI) Vol. 5, No. 1, February 2016

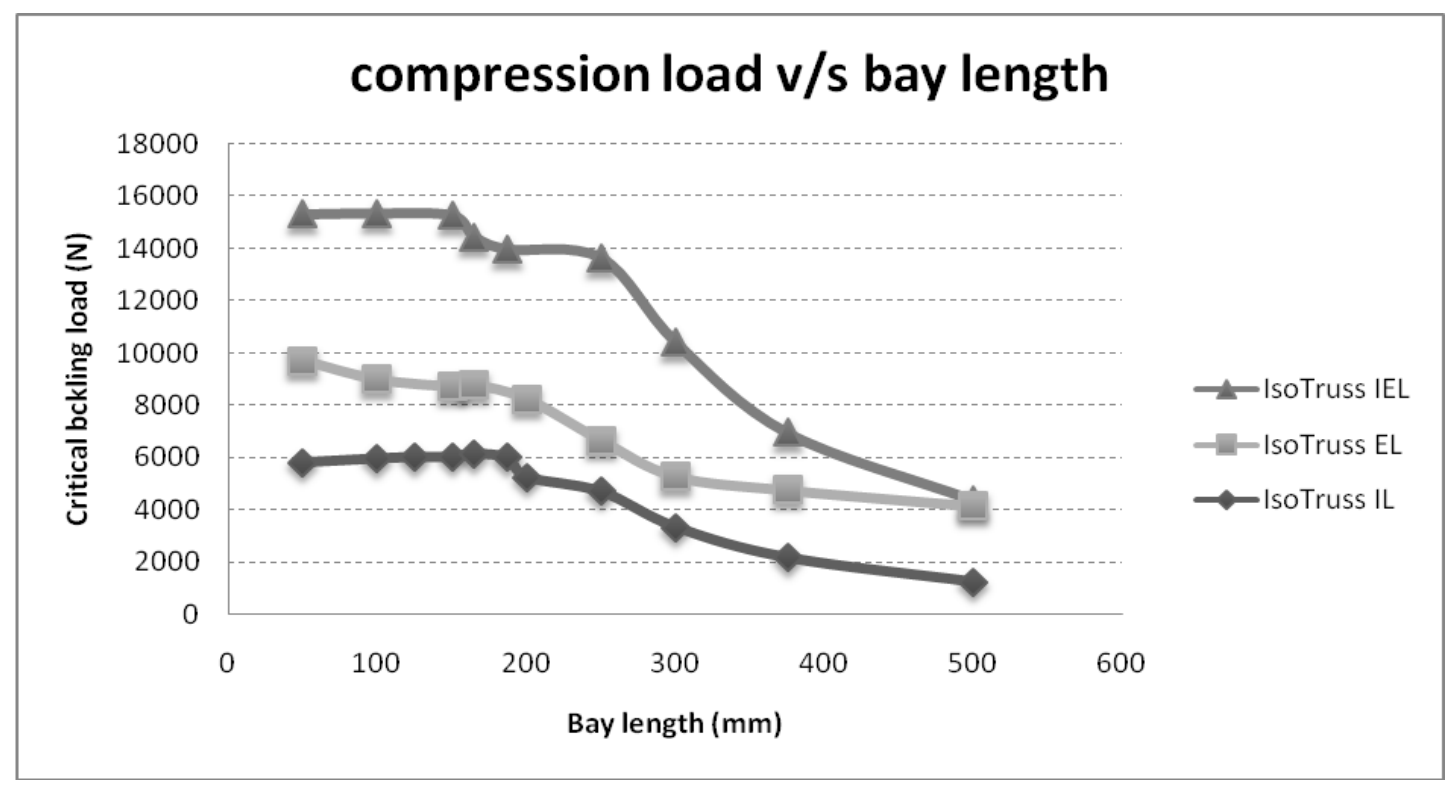

Figure 6. Compressive Load vs. bay length of IsoTruss

Figure 7 shows the deformed shape for the first mode of buckling of IsoTruss IL, EL and IEL with $100 \mathrm{~mm}$ bay length. The shape indicates a global buckling behaviour.

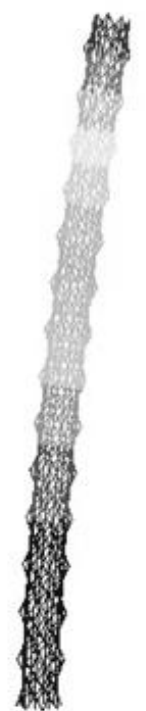

(a) IL

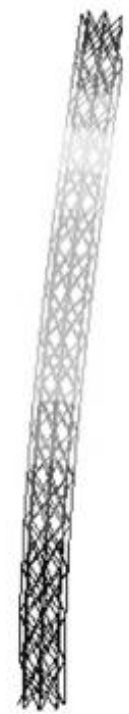

(b) EL

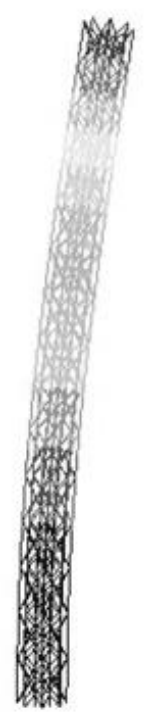

\begin{tabular}{|c|c|}
\hline $\begin{array}{l}\text { 100mm Bay } \\
\text { Length } \\
\text { IsoTruss Type }\end{array}$ & $\begin{array}{l}\text { Critical } \\
\text { Buckling } \\
\text { Load (N) }\end{array}$ \\
\hline (a) IL & 5967.0 \\
\hline (b) EL & 8989.2 \\
\hline (c) IEL & 15357.0 \\
\hline
\end{tabular}

Figure 7. First buckling mode shapes for $100 \mathrm{~mm}$ bay length

Figure 8 shows deformed shape of IsoTruss IL, EL and IEL with bay length $200 \mathrm{~mm}$ for the first mode of buckling. IsoTruss IL, EL shows the local buckling and IEL shows the global buckling behaviour. Figure 9 shows deformed shape of IsoTruss IL, EL and IEL with bay length $300 \mathrm{~mm}$ for the first mode of buckling. It indicates localization of deformation in the IsoTruss. 
International Journal on Cybernetics \& Informatics (IJCI) Vol. 5, No. 1, February 2016

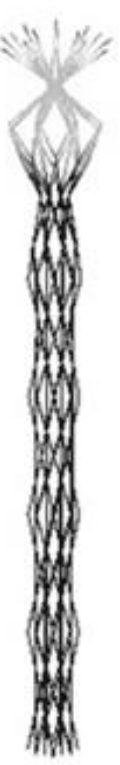

(a) IL

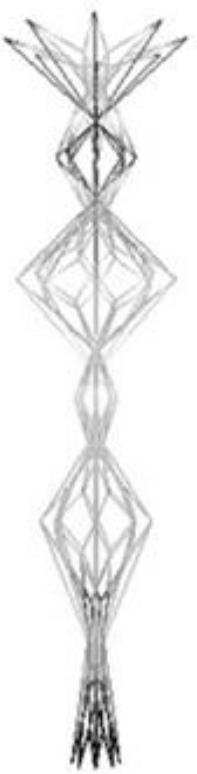

(b) EL

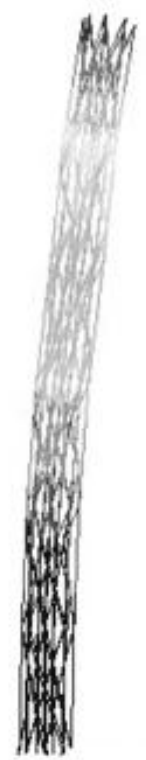

\begin{tabular}{|c|c|}
\hline $\begin{array}{l}250 \mathrm{~mm} \text { Bay } \\
\text { Length } \\
\text { IsoTruss Type }\end{array}$ & $\begin{array}{l}\text { Critical } \\
\text { Buckling } \\
\text { Load (N) }\end{array}$ \\
\hline (a) IL & 4699.2 \\
\hline (b) EL & 6663.9 \\
\hline (c) IEL & 6663.9 \\
\hline
\end{tabular}

(c) IEL

Figure 8. First buckling mode shapes for $250 \mathrm{~mm}$ bay length

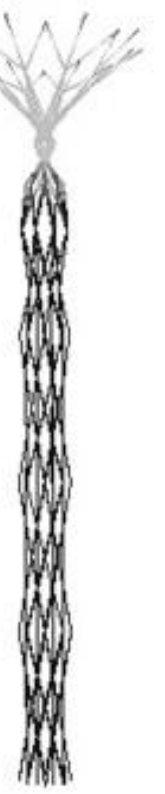

(a) IL

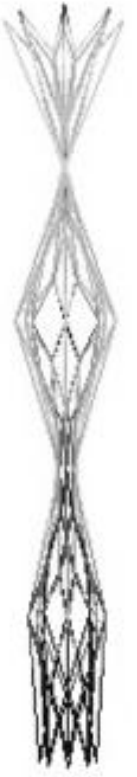

(b) EL

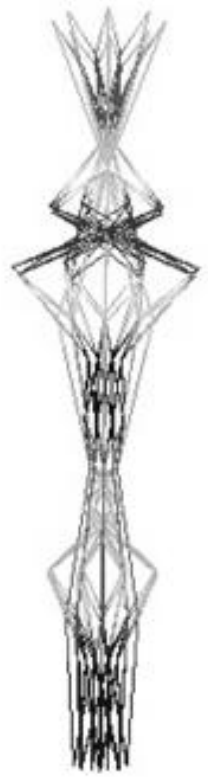

\begin{tabular}{|c|c|}
\hline $\begin{array}{l}\text { 300mm Bay } \\
\text { Length } \\
\text { IsoTruss Type }\end{array}$ & $\begin{array}{l}\text { Critical } \\
\text { Buckling } \\
\text { Load (N) }\end{array}$ \\
\hline (a) IL & 3338.7 \\
\hline (b) EL & 5284.7 \\
\hline (c) IEL & 10425.0 \\
\hline
\end{tabular}

(c) IEL

Figure 9. First buckling mode shapes for $300 \mathrm{~mm}$ bay length 


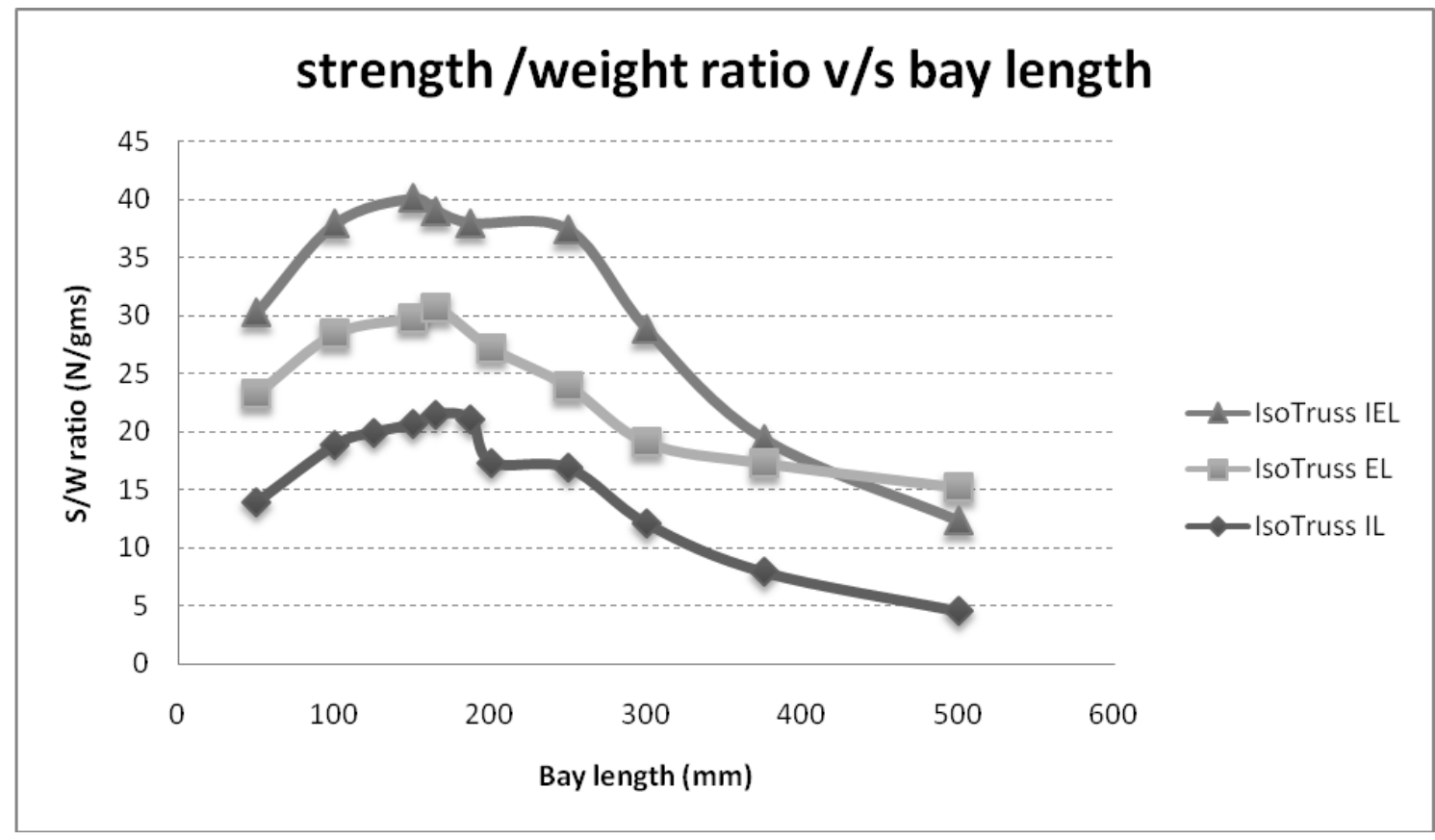

Figure 10. Strength to Weight ratio vs. Bay length of IsoTruss

The Figure 10 shows the strength to weight ratio as a function of bay length. The IsoTruss IL and IsoTruss EL have same weight as they have eight longitudinal members each which are just placed at different distance from axis of IsoTruss. But IsoTruss IEL have a slightly greater weight than the IL \& EL because it has 16 longitudinal members. This greater number of longitudinal member of IsoTruss IEL gives it the unique strength. Hence it has a higher strength to weight ratio than the remaining type even though being the heaviest among the types considered. From the Figure 11 it could also be observed that all the three types of IsoTruss considered in the analysis exhibits a higher strength to weight ratio roughly at $170 \mathrm{~mm}$ bay lengths.

\section{CONCLUSiON}

Material used in the present study is $24 \mathrm{~K}$ carbon fibre cordage impregnated with epoxy resin. Material property used in the FE analysis is obtained by tensile test of several specimens in UTM machine. Comparative compressive buckling load carrying capacity of three different types of 8noded IsoTruss namely IsoTruss-IL, IsoTruss-El, and IsoTruss IEL is examined with progressive bay length. In the IsoTruss-IL longitudinal members positioned at the base of the tetrahedron, in the IsoTruss-EL longitudinal members positioned at the vertex of the tetrahedron abbreviated as EL, where as in the IsoTruss-IEL longitudinal members positioned at the base as well as vertex of the tetrahedron. It is observe for 50 to $150 \mathrm{~mm}$ bay length buckling load is all most constant for all three types of IsoTruss. All three types of IsoTruss exhibit a global buckling for a range of bay lengths from $50 \mathrm{~mm}$ to $200 \mathrm{~mm}$. From 200 to $300 \mathrm{~mm}$ bay lengths there is a transition zone of global to local deformation. IsoTruss's with bay lengths greater than $300 \mathrm{~m}$ shows local buckling behaviour and also exhibit a very small compressive buckling load carrying capacity before buckling. It is also observe that IsoTruss-IEL have better compressive buckling load carrying capacity and better strength to weight ration compare to other two type of IsoTruss. 
International Journal on Cybernetics \& Informatics (IJCI) Vol. 5, No. 1, February 2016

\section{REFERENCES}

[1] Weaver Thomas J., (1999) "Mechanical characterization of a graphite/epoxy IsoTruss subject to simple and biaxial loads", M.S. Thesis, Brigham Young University, Provo, Utah.

[2] Yoder Jacob A., (2000) "IsoTruss to IsoTruss connections and small scale IsoTruss design for mountain bike frames", S. Thesis, Brigham Young University, Provo, Utah.

[3] Jones Layne S., (2000) "Flexural behaviour of spirally consolidated double IsoTruss reinforced concrete beams", M.S. Thesis, Brigham Young University, Provo, Utah.

[4] Jarvis David, (2001) "Development of a rectangular IsoTruss for reinforced concrete beams", M.S. Thesis, Brigham Young University, Provo, Utah.

[5] Phillips Joseph K, (2001) "IsoTruss bicycle frame design using beam theory and shear flow analysis", M.S. Thesis, Brigham Young University, Provo, Utah.

[6] Rackliffe Mary E, (2002) "Development of ultra-lightweight IsoTruss grid structures”, M.S. Thesis, Brigham Young University, Provo, Utah.

[7] Mary E. Racliffe, David W. Jesen, Warren K. Lucas, (2005) "Local and global buckling of ultra-light weight IsoTruss structures”, Composites Science and Technology, Vol. 66, No. 5, pp. 282-288. 